Disclosure of Interests: None declared

DOI: 10.1136/annrheumdis-2019-eular.4257

\section{AB0821 $\quad$ APPRECIATION OF OSTEOPOROTIC TREATMENT COMPLIANCE WITH ALENDRONATE 7OMG ORALLY}

Bilal Bengana, Abdenour Boukabous, Naima Bahaz, Salima Lefkir. University Hospital of Benimessous, Rheumatology, Algiers, Algeria

Background: Patients suffering from osteoporosis (OP) dont have the opportunity to enjoy from an accurate and concrete parameters response to OP treatment. They therefore have no palpable evidence of the favorable effect generated by anti- osteoporotic treatment (AOT), given the silent nature of the pathology. That is way we see the non-compliance with treatment in some patients.

Objectives: It was essential to estimate the extent of the lack of compliance with AOT in order to deduce the factors related to this deficiency in order to reduce the size of the problem.

Methods: Its a Descriptive cross study performed in all patients over 38 years for both sexes and that exhibit post menopausal or corticosteroidinduced OP justifying AOT orally ( alendronate $70 \mathrm{mg}$ oraly per week) observed over a period of at least 6 months.

Results: We collected data of 153 patients, in 9 out of 10 cases this was a woman, the mean age was $59.3 \pm 8.1$ years, the average duration of gain of treatment was $32.2 \pm 18.2$ months, 3 of 5 patients believe that treatment is for musculoskeletal pains, $1 / 3$ of respondents confess not to take their weekly treatment regularly, regular physical activity was performed by only $21 \%$ of patients, the factors related to non-compliance were : lack of education $(p=0,032)$ and sedentary lifestyle $(p=0,044)$.

Conclusion: OP is unfortunately underestimated by both patients and physicians, and its short- and long- term repercussions are often minimized. Our study has shown that the various measures required in its management are poorly followed by patients despite their proven effectiveness in reducing fractures.One in three patients in ours ample do not follow their treatment properly. Therapeutic education seems to be the answer to overcome this lack of adhesion.

Disclosure of Interests: None declared

DOI: 10.1136/annrheumdis-2019-eular.3826

\section{AB0822 RHEUMATIC DISEASESRECEIVING TREATMENT WITH ADALIMUMAB. DESCRIPTIVE STUDY OF A COHORT}

Boris Anthony Blanco Cáceres,Paula García Escudero, Javier Arostegui Lavilla, Mayra Nathali Rivas Zavaleta, Marta González Fernández. Hospital Universitario Cruces, Rheumatology, Barakaldo, Spain

Background: Patients with chronic rheumatic diseases (CRD) have lower levels of $250 \mathrm{HD}$, inverse correlation has been describe and greater severity between the different CRD with 25OHD deficit. Most scientific societies recommend levels $>30 \mathrm{ng} / \mathrm{mL}$. Patients with refractary disease to conventional therapy have a higher inflammatory load, require optimal levels of $25 \mathrm{OHD}$ and often needs biological disease-modifying antirheumatic drugs (bDMARD) in order to prevent structural damage.

Objectives: The aim of this study was to describe the epidemiological, clinical and therapeutic characteristics of patients receiving Adalimumab (ADL) in which 25OHD levels were determined in 2018.

Methods: Transversal, retrospective study in a hospital setting. We analyzed data from patients included in a study to determine levels of ADL, in whom the serum level of $250 H D$ was determined at least once during the last year. Among 104 patients, 74 with 25OHD determination were included.

Results: Seventy-four patients selected, 45.9\% were men and 54.1\% women. The mean age was 54.9 years (SD \pm 13.6$)$. $41.9 \%$ (31) had Rheumatoid Arthritis, 36.5\% (27) Spondyloartrhitis, $17.6 \%$ (13) Psoriatic Arthritis and $4.1 \%$ (3) Juvenile Idiopathic Arthritis. $35.1 \%$ (26) had deficit $(<20 \mathrm{ng} / \mathrm{mL})$ of $25 \mathrm{OHD}, 31.1 \%$ (23) insufficiency $(20-30 \mathrm{ng} / \mathrm{mL})$ and only $33.8 \%$ (25) optimal levels $(>30 \mathrm{ng} / \mathrm{mL})$. The $62.2 \%(46)$ of the patients received oral supplementation, of these $67.4 \%$ maintained levels $>20 \mathrm{ng} /$ $\mathrm{mL}$ and $32.6 \%<20 \mathrm{ng} / \mathrm{mL}$. $37.8 \%$ (28) did not receive supplementation, despite this $60.7 \%$ within this group had levels $>20 \mathrm{ng} / \mathrm{mL}$. No statistical differences were found regarding vitamin $\mathrm{D}$ deficit and oral supplementation $(p>0.05)$

$13.5 \%$ (10) of the patients also had Osteoporosis (OP); in this group 6 had deficit of $25 \mathrm{OHD}, 1$ insufficiency and only 3 optimal levels, all of them received 25OHD supplementation. No differences between the groups in relation to the DMARD treatment.

Conclusion: Vitamin D levels were determined in $71.2 \%$ of patients and not in all of them as it would be advisable. Among the patients with $25 \mathrm{OHD}$ determination, $62.2 \%$ received oral supplementation, however only $33.8 \%$ of the patients reached optimal levels (>30 ng/mL) without statistical differences regarding supplementation. $13.5 \%$ of the patients who received supplementation also had $\mathrm{OP}$

Despite the weakness of the study in terms of design and sample, most patients did not reached optimal levels of $250 \mathrm{HD}$; we can assume that it is necessary to obtain levels of $250 \mathrm{HD}>30 \mathrm{ng} / \mathrm{mL}$ in all patients, with adequate supplementation if necessary due to the positive effects known in CRD.

\section{REFERENCES}

[1] Fernandes S1, Etcheto A2, van der Heijde D3, Landewé R4, van den Bosch F5, Dougados M2, Moltó A2. Vitamin D status in spondyloarthritis: results of the ASAS-COMOSPA international study. Clin Exp Rheumatol. 2018 Mar-Apr;36(2):210-214

[2] Lin J1, Liu J1, Davies ML2, Chen W1. Serum Vitamin D Level and Rheu matoid Arthritis Disease Activity: Review and Meta-Analysis. PLoS One. 2016 Jan 11;11(1):e0146351

[3] Dawson-Hughes B1, Mithal A, Bonjour JP, Boonen S, Burckhardt P, Fulei han GE, Josse RG, Lips P, Morales-Torres J, Yoshimura N. IOF position statement: vitamin D recommendations for older adults. Osteoporos Int. 2010 Jul;21(7):1151-4

[4] Bischoff-Ferrari HA1, Giovannucci E, Willett WC, Dietrich T, DawsonHughes B. Estimation of optimal serum concentrations of 25-hydroxyvitamin D for multiple health outcomes. Am J Clin Nutr. 2006 Jul;84(1):18-28.

Disclosure of Interests: None declared

DOI: 10.1136/annrheumdis-2019-eular.7012

\section{AB0823 TRABECULAR BONE SCORE AT LUMBAR SPINE IS ASSOCIATED WITH QUANTITATIVE ULTRASOUND MEASUREMENTS AT PHALANGEAL SITE IN BREAST CANCER SURVIVORS RECEIVING AROMATASE INHIBITORS}

Antonino Catalano ${ }^{1}$, Federica Bellone ${ }^{1}$, Rita Maria Agostino $^{2}$, Nunziata Morabito ${ }^{1}$, Agostino Gaudio ${ }^{3}$, Antonino Lasco ${ }^{1} .{ }^{1}$ University of Messina, Department of Clinical and Experimental Medicine, Messina, Italy, ${ }^{2}$ Medical Oncology Unit, Grand Metropolitan Hospital "Bianchi Melacrino Morelli", Reggio Calabria, Italy, ${ }^{3}$ University of Catania, Department of Clinical and Experimental Medicine, Catania, Italy

Background: In breast cancer $(\mathrm{BC})$ survivors, the age-related reduction in bone mineral density is exacerbated by aromatase inhibitors (Als) treatment. Als disrupt also bone quality and enhance fracture risk in aging women. Consequently, bone health evaluation is mandatory in BC women receiving Als.

Objectives: Quantitative ultrasound of bone (QUS) and trabecular bone score (TBS) are recognized tools to explore bone health beyond bone mineral density (BMD). The aim of our research was to explore the association of TBS with QUS measurements at phalangeal site in a setting of postmenopausal women taking aromatase inhibitors (Als).

Methods: BMD at lumbar spine, femoral neck and TBS were evaluated by a DXA densitometer (Hologic Discovery). Amplitude Dependent Speed of Sound (AD-SoS), Bone Transmission Time (BTT) and Ultrasound Bone Profile Index (UBPI) were detected at phalangeal site by Bone Profiler (Igea).

Results: In 102 postmenopausal women (mean age $61.64 \pm 8.33$ yr.) (60 Als treated and 42 controls), at baseline examination, TBS was negatively associated with age $(r=-0.39, p<0.001)$ and positively related with T-score values at lumbar spine and femoral neck. After 18 months, ADSoS, UBPI and BTT values were significantly decreased in BC women receiving Als $(-3.7 \%,-6.45 \%,-8.5 \%$, respectively, $\mathrm{p}<0.001$ for all), but not in controls $(-0.7 \%,-3.53 \%,-2.97 \%$, respectively). Change of BMD at lumbar spine was significantly different between Als treated women and controls $(-2.94 \%$ vs. $-0.69 \%, p=0.001)$ and the same result was observed as for $\mathrm{BMD}$ at femoral neck $(-2.5 \%$ vs. $-0.39 \%, \mathrm{p}=0.01)$. Percent change of TBS was significantly greater in Als treated women in comparison with controls $(-2.2 \%$ vs. $-0.4 \%$, respectively, $\mathrm{p}=0.02)$. In Als treated women, but not in controls, CTX levels significantly increased after 18 months [0.47 (0.36 to 0.62$)$ vs. $0.66(0.43$ to 0.77$), \mathrm{p}=0.0004]$ and the same trend was observed as for BSAP levels [14 (13.01 to 15.57) vs. 15 (13.75 to 16.75), $p=0.003$ ]. At a multiple regression analysis, change of TBS was independently predicted by change of AD-SoS, after correcting 
for BMD change at lumbar spine and femoral neck and for modification of CTX and BSAP levels $(\beta=0.37, \mathrm{SE}=2.44, \mathrm{p}<0.001)$.

Conclusion: TBS variation was independently predicted by phalangeal QUS measurement in Als treated BC women. Phalangeal QUS may represent an alternative tool to evaluate bone health also in this setting of patients.

\section{REFERENCES}

[1] Catalano A, Morabito N, Agostino RM, Basile G, Gaudio A, Atteritano M, Natale G, Xourafa A, Morini E, Adamo V, Lasco A. Bone health assessment by quantitative ultrasound and dual-energy $x$-ray absorptiometry in postmenopausal women withbreast cancer receiving aromatase inhibitors. Menopause. 2017 Jan;24(1):85-91.

[2] Catalano A, Morabito N, Basile G, Fusco S, Castagna G, Reitano F, Albanese RC, Lasco A. Fracture risk assessment in postmenopausal women referred to an Italian center for osteoporosis: a single day experience in Messina. Clin Cases MinerBone Metab. 2013 Sep;10(3):191-4.

[3] Martineau P, Leslie WD. Trabecular bone score (TBS): Method and applications. Bone. 2017 Nov;104:66-72.

Disclosure of Interests: None declared

DOI: 10.1136/annrheumdis-2019-eular.4334

\section{AB0824 THE EFFECTS OF CEMENT VOLUME DISTRIBUTION OF PERCUTANEOUS KYPHOPLASTY IN OSTEOPOROTIC VERTEBRAL FRACTURE}

Keng Chen ${ }^{1}$, Ram Chaudhary ${ }^{2}$, Zhaopeng Cai ${ }^{1}$, Lin Huang ${ }^{2}$, Zhongyu Xie ${ }^{1}$, Peng Wang ${ }^{1}$, Huiyong Shen ${ }^{1} .{ }^{1}$ The Eighth Affiliated Hospital, Sun-Yat-Sen University, Orthopedic Department, Shenzhen, China; ${ }^{2}$ Sun Yat-sen Memorial Hospital, Sun-Yat-Sen University., Orthopedic Department, Guangzhou, China

Background: Osteoporotic vertebral compression fractures (OVCF) account for $45 \%$ of osteoporotic fractures. It cause severe back pain, unable walk or even stand Percutaneous kyphoplasty (PKP) is commonly used to treat painful OVCF, effective relieve pain and walking ability. But there have been few clinical studies that have specifically explored the relationship of the cement volume distribution rate and clinical outcomes.

Objectives: To access the effect of the cement volume distribution pattern in percutaneous kyphoplasty.

Methods: We retrospectively reviewed 126 cases of osteoporotic compression fractures treated with percutaneous kyphoplasty from Jan 2005 to May 2015. The cement volume distribution (CVD) was measured with $X$ ray and CT scan. 126 thoracolumbar vertebrae were divided into two groups based on CVD ratio: 51 vertebrae in group $A$ with $C V D$ ratio $<=2$; 15 in group B with CVD ratio>2. The relationships of the cement volume distribution and clinical outcomes of pain, vertebral height and kyphotic angle change between the two groups were compared

Results: The mean duration of follow-up was 25 months (range 11 76), and the mean age was $68.2 \pm 8.7$ years. Correlation of volume of cement distribution measured by CT scan and $\mathrm{X}$-ray is $89.3 \% \quad(\mathrm{P}<0.001)$. The VAS improvement after kyphoplasty was no statistically significant $(P=$ 0.651). Statistically greater height gain was observed in group $B$ at the anterior border $(4.42 \pm 2.42$ VS $1.83 \pm 1.5, P=0.035)$ and at the center $(4.64 \pm 1.73$ VS $3.01 \pm 0.41, P=0.044)$. Subsequent fracture was 7 cases in group $A$ and 4 case in group $B$.

Conclusion: Larger volume of cement distribution, greater correction of kyphosis. The greater distribution of the cement without leakage would be suggested when the limited volume of cement is injected.

\section{REFERENCES}

[1] Rebolledo B J, Gladnick B P, Unnanuntana A, et al. Comparison of unipedicular and bipedicular balloon kyphoplasty for the treatment of osteoporotic vertebral compression fractures A prospective randomised study[J]. Bone Joint J, 2013, 11(3):401-406.

[2] Lian-Hua L I, Tian-Sheng S, Zhi L, et al. Comparison of unipedicular and bipedicular percutaneous kyphoplasty for treating osteoporotic vertebral compression fractures: a meta-analysis[J]. Chin Med J (Eng), 2013, 126 (20).

[3] Song B K, Eun J P, Oh Y M. Clinical and radiological comparison of unipedicular versus bipedicular balloon kyphoplasty for the treatment of vertebral compression fractures[J]. Osteoporosis International, 2009, 20(10):17171723.

Acknowledgement: National Natural Science Foundation (81703163) Disclosure of Interests: None declared

DOI: 10.1136/annrheumdis-2019-eular.3439

\section{$\mathrm{AB} 0825$}

\section{IMPACT OF AROMATASE INHIBITOR TREATMENT ON} BONE MINERAL DENSITY AND PREVALENT VERTEBRAL FRACTURE

Cyrine Daldoul ${ }^{1}$, Nejla El Amri ${ }^{1}$, Sadok Laataoui ${ }^{1}$, Khadija Baccouch ${ }^{1}$, Imtinen Belaid ${ }^{2}$, Hela Zeglaoui ${ }^{1}$, Elyes Bouajina ${ }^{1} .{ }^{1}$ Farhat Hached Hospital, Rheumatology, Sousse, Tunisia; ${ }^{2}$ Farhat Hached Hospital, Oncology, Sousse, Tunisia

Background: In recent years, despite the growing incidence of breast cancer, a reduction in mortality has been observed. Adjuvant therapy with aromatase inhibitors (Al) has contributed to a longer disease free survival. However these molecules induce a hyper bone remodeling, modifying the bone architecture and thus increasing the fracture risk. The new guidelines indicate extension of treatment duration up to 10 years. So specia precautions must be established in order to avoid bone mineral density $(B M D)$ decrease and to reduce fracture risk.

Objectives: The aim of this study was to evaluate the impact of Al treatment on BMD and to screen vertebral fracture (VF) in post menopausal women with breast cancer.

Methods: A clinical cross sectional study was carried between August 2018 and December 2018, including post-menopausal women with nonmetastatic breast cancer. Each woman had an extensive medical history and physical examination. BMD was measured using dual energy $X$ absorptiometry DeXa at femoral neck, total hip and at lumbar spine. We used the WHO criteria for the diagnosis of osteoporosis and osteopenia. Vertebral fractures were screened by performing a vertebral fracture (VFA) image. VF grade 1 were excluded.

Results: Thirty-six post-menopausal women were examined in our rheu matology department. The mean age was $59.5 \pm 10.38$ years with an average body mass index (BMI) of $30.7 \mathrm{~kg} / \mathrm{m}^{2}$ [15.81-38.28].The average age of menopause was $45.5 \pm 5.25$ years. The mean length of menopause was 14 years [2.1-31]. The mean duration of breast cancer follow-up was 71.7 months. 22 patients underwent chemotherapy and radiotherapy. Mean femoral neck BMD was $0.805 \mathrm{~g} / \mathrm{cm}^{3}\left[0.647-1.049 \mathrm{~g} / \mathrm{cm}^{3}\right]$ and the vertebral BMD was $1.003 \mathrm{~g} / \mathrm{cm}^{3}\left[0.739-1.314 \mathrm{~g} / \mathrm{cm}^{3}\right]$.According to the WHO classification, 12 women $(34.6 \%)$ had osteoporosis, 15 (42.3\%) had osteopenia and $9(19.2 \%)$ had normal BMD. 9 patients showed signs of osteoporosis at femoral neck and 8 had osteoporosis at lumbar spine. 10 subjects $(27.8 \%)$ had VF identified by VFA, which were grade 2 and 3 in respectively 8 and 2 vertebra. No multiple VF were assessed. No statistically significant difference was found between women with and without VF for age, BMD value, and duration of follow-up or previous fragility fracture. We did not find a significant correlation between treatment length and BMD at either site: femoral neck $(p=0.42)$, total hip $(p=0.783)$ and lumbar spine $(\mathrm{p}=0.357)$.

Conclusion: This data has shown that approximately one-third of patients receiving Al treatment have at least one vertebral fracture, and $40 \%$ had osteoporosis. Therefore we need to screen bone mineral density and fracture in women under $\mathrm{Al}$ therapy.

Disclosure of Interests: None declared

DOI: 10.1136/annrheumdis-2019-eular.8045

\section{AB0826 OSTEODENSITOMETRIC PROFILE DURING JUVENILE CELIAC DISEASE}

Cyrine Daldoul, Nejla El Amri, Sadok Laataoui, Khadija Baccouch, Hela Zeglaoui, Elyes Bouajina. Farhat Hached Hospital, Rheumatology, Sousse, Tunisia

Background: Bone mineralization abnormalities are often seen in children with chronic gastrointestinal disease.

Among these pathologies, celiac disease (CD) is the most likely source of abnormalities of bone mineral density. These disorders are of multifactorial origin involving malabsorption, nutritional status, decreased physical activity and chronic inflammation.

Objectives: The purpose of this study was to determine the frequency and factors associated with lower bone mineral density in children with CD.

Methods: This is a retrospective study, over a period of 4 years (from January 2014 to December 2017) including children followed for CD who had a measurement of bone mineral density (BMD) by DEXA. Clinical, anthropometric and densitometry data (BMD at the femoral and vertebral site) were recorded.

Results: Thirty-six children were collected. Among them 29 were girls and 7 were boys. The average age was 11.94 years old.

The average size was $137.8 \mathrm{~cm}$. The average weight was $35.3 \mathrm{~kg}$. The average body mass index (BMI) was $17.69 \mathrm{~kg} / \mathrm{m}^{2}$ [13.05-21.69 kg/m²]

The average vertebral BMD was $0.891 \mathrm{~g} / \mathrm{cm} 3$. The average $\mathrm{z}$-score was -1.08. BMD was normal in 26 cases. A decrease in bone mineral density 